\title{
Mechanism of cell death induced by silica nanoparticles in hepatocyte cells is by apoptosis
}

\author{
YE YANG $^{1,2^{*}}$, XINJING DU ${ }^{1,2^{*}}$, QIANG WANG $^{3}$, JIANWEI LIU $^{4}$, ENGUO ZHANG $^{1,2}$, LINLIN SAI $^{2}$, \\ CHENG PENG ${ }^{2,5}$, MARTIN F. LAVIN ${ }^{2,6}$, ABREY JIE YEO ${ }^{2,6}, \mathrm{XU} \mathrm{YANG}^{2}$, HUA SHAO $^{2}$ and ZHONGJUN DU ${ }^{2}$ \\ ${ }^{1}$ School of Medicine and Life Sciences, University of Jinan-Shandong Academy of Medical Sciences; ${ }^{2}$ Department of \\ Toxicology, Shandong Academy of Occupational Health and Occupational Medicine, Shandong Academy of \\ Medical Sciences, Jinan, Shandong 250062; ${ }^{3}$ Department of Preventive Medicine and Public Health Laboratory Science, \\ School of Medicine, Jiangsu University, Zhenjiang, Jiangsu 212013; ${ }^{4}$ Radiation Protection Safety Institute, \\ Shandong Center for Disease Control and Prevention, Jinan, Shandong 250014, P.R. China; ${ }^{5}$ Queensland Alliance for \\ Environmental Health Sciences (QAEHS), University of Queensland, Brisbane, Queensland 4108; ${ }^{6}$ University of \\ Queensland Centre for Clinical Research (UQCCR), University of Queensland, Brisbane, Queensland 4006, Australia
}

Received January 22, 2019; Accepted July 1, 2019

DOI: $10.3892 /$ ijmm.2019.4265

\begin{abstract}
Silicon is one of the most widely used chemical materials, and the increasing use of silica nanoparticles (SNs) highlights the requirement for safety and biological toxicity studies. The damaging and adverse effects of SNs on human hepatocytes remain largely unknown, as do the mechanisms involved. In the present study, the mechanisms underlying $\mathrm{SN}$-induced toxicity in the human hepatocyte cell line HL-7702 were investigated. An MTT assay revealed that following exposure to SNs in the concentration range of $25-200 \mu \mathrm{g} / \mathrm{ml}$, the viability of HL-7702 cells decreased, and the viability decreased further with increasing exposure time. SNs induced a delay in the $\mathrm{S}$ and $\mathrm{G} 2 / \mathrm{M}$ phases of the cell cycle, and also induced DNA damage in these cells. Western blot and flow cytometry analyses revealed that cell death was mediated by mitochondrial damage and the upregulated expression of a number of pro-apoptotic proteins. In conclusion, exposure to SNs led to mitochondrial and DNA damage, resulting in
\end{abstract}

Correspondence to: Professor Hua Shao or Dr Zhongjun Du, Department of Toxicology, Shandong Academy of Occupational Health and Occupational Medicine, Shandong Academy of Medical Sciences, 18877 Jingshi Road, Jinan, Shandong 250062, P.R. China E-mail: chinashaohua5888@163.com

E-mail: duzj1981@163.com

*Contributed equally

Abbreviations: SNs, silica nanoparticles; Cyt C, cytochrome C; ROS, reactive oxygen species; DSB, double strand breaks; H\&E, hematoxylin and eosin; FCM, flow cytometry; MMP, mitochondrial membrane potential; SCGE, single-cell gel electrophoresis

Key words: silica nanoparticles, human hepatocyte cells, cytotoxicity, apoptosis, mechanism apoptosis-mediated HL-7702 cell death. The study provided evidence for the cellular toxicity of SNs, and added to the growing body of evidence regarding the potential damaging effects of nanoparticles, indicating that caution should be exercised in their widespread usage.

\section{Introduction}

Nanomaterials are ultrafine particle materials whose structural units are 1-100 $\mathrm{nm}$ in size (1). They have four basic characteristics: Volume, surface, quantum size, and quantum tunneling effects, providing them with the capacity to serve important roles in various fields, including magnetic, optical, electrical, biological and medical fields (2). As a novel tool, nanotechnology has enabled the widespread use of silica nanoparticles (SNs) in the biomedical field, including in drug delivery, imaging and other therapeutic applications (3). For example, the ability to modulate Janus particle aggregation in response to a range of stimuli, in combination with the high resolution and deep penetration of multiwavelength photoacoustic imaging, is attractive for a broad range of applications in diagnostic imaging and theranostics (4). The inherent low level of toxicity and small particle size enable SNs to enter the blood circulation and be used for drug administration and transportation in treatment protocols (5).

SNs are one of the most widely used nanopowder materials, with the highest yield in large-scale industrial production in the world (6). The use of SNs in the development of nanotechnology requires close monitoring of their toxicity and biological effects to ensure safe application. Human exposure to SNs through environmental, occupational and iatrogenic processes demands appropriate scrutiny to avoid the incidence of adverse effects $(7,8)$. The safe use of SNs requires improved understanding of their interactions with cells, and their use in animal models provides the basis for toxicity assessments.

Although SNs, with low toxicity, serve a universal and important role in a variety of human processes and living 
organisms, they have the potential to accumulate in the organism (9). Long-term exposure to low-dose, or short-term exposure to higher-dose nanomaterials can lead to poisoning of the organism (10). Previous studies have reported that SNs exhibit the potential to induce cytotoxicity, oxidative stress and apoptosis in human cells $(11,12)$. Inhalation and skin contact are common exposure routes via which SNs deposit in the lungs and on the skin, inducing inflammation, fibrosis and cytotoxicity (13). The cytotoxic effects of SNs arise due to oxidative stress and DNA damage (14). Our previous study revealed that SNs enter the human body via the respiratory system, acting on the cardiovascular system, lungs and other body tissues, inducing myocardial cytotoxicity or pulmonary fibrosis (15). One study found that 15 - and 46-nm SNs both significantly reduced the viability of bronchoalveolar carcinoma-derived cells compared to the control groups, in a dose- and time-dependent manner by causing oxidative stress (16). An animal study revealed that SNs injected intraperitoneally in mice were distributed in the brain, liver, heart and reproductive systems, and that toxicity varied in different organs (17). In addition to the established cardiovascular toxicity, pulmonary toxicity, reproductive toxicity and neurotoxicity have been observed $(18,19)$; however, to what extent SNs affect other organs and tissues remains unclear.

Apoptosis is a common method of programmed cell death, characterized by depolymerization of the cytoskeleton, cell shrinkage, chromatin condensation, nuclear fragmentation and transport of phosphatidylserine to the cell surface (20). Its cytological features include nuclear condensation and DNA fragmentation (21). Nanoparticles can disrupt normal cellular function via cytotoxic stress, and are responsible for membrane damage (22). There are several genes and proteins reported to be involved in apoptotic pathways. Proteins of the Bcl-2 family comprise proapoptotic and antiapoptotic regulators of programmed cell death; the intended action mode of each component protein is to protect or destroy mitochondrial integrity, thereby activating or inhibiting the release of downstream factors, such as cytochrome $\mathrm{C}$ (Cyt $\mathrm{C}$ ), thus resulting in the activation of caspase-3 (23). The Bcl-2/Bax ratio determines whether cell survival or apoptotic cell death occurs, and is an indicator of the strength of apoptosis (24). Detection of apoptosis using these common markers can increase the confidence and accuracy of assays. Another form of programmed cell death, autophagy, involves the clearing of damaged organelles to promote cell survival; however, whereas it is an emergency survival state, a complex interplay has been reported between autophagy and apoptosis in mammalian cells (25). Primarily, apoptosis represents cell death and autophagy cell survival, but it has been suggested that autophagy can precede, or even activate, apoptosis, by inducing the activation of caspases or the depletion of endogenous apoptosis inhibitors. SN-induced autophagy has been described previously and associated with the generation of reactive oxygen species (26), although whether SNs can induce apoptosis requires further investigation.

The liver is the most important detoxifying organ; it removes toxins from the circulation prior to excretion, and is the target organ for numerous poisons (27). Protecting the health of, and alleviating the burden on the hepatic system is a key focus in life science research. There is evidence that SNs can accumulate in the liver and cause severe damage following intravenous administration (28). Intranasal administration of SNs resulted in reduced levels in the blood compared with intravenous administration, but substantial quantities were still detectable in the liver, providing further evidence that SNs accumulate in the liver (29). Following intraperitoneal injection of mice with SNs, the nanoparticles distributed to the liver, heart, spleen, lung and kidney, inducing acute and chronic liver injury (17). Similar studies were also conducted in vitro, demonstrating that SNs can induce oxidative stress in HepG2 human liver cancer cells at 3 and $24 \mathrm{~h}$ following treatment, suggesting that an oxidative stress-mediated mitochondrial pathway, leading to apoptosis, may contribute to hepatotoxicity (30). In addition, Kupffer cells can be activated by SNs releasing bioactive mediators, such as reactive oxygen species (ROS), tumor necrosis factor- $\alpha$ and nitric oxide, which may also contribute to hepatotoxicity (31). $\mathrm{TiO}_{2}$ nanoparticles were considered to induce apoptosis, hypothetically due to effective activation of caspases-3 and -9, downregulation of Bcl-2 gene and protein levels, upregulation of Bax and Cyt $\mathrm{C}$ protein, and promoted accumulation of ROS (32). There is substantial evidence that SNs can cause liver damage (33); however, the mechanisms via which hepatotoxicity occurs remain unclear.

In this study, the HL-7702 cell line was used as a model system to explore the $\mathrm{SN}$ - induced death of human hepatocytes and investigate the mechanisms involved. Increasing concentrations of SNs resulted in a significantly increased degree of cell death, which was determined to occur via apoptosis. SN exposure led to cell cycle arrest in the S and G2 phases and caused double-strand breaks (DSBs) in DNA. A decrease in the mitochondrial membrane potential (MMP) was also observed, indicating mitochondrial involvement in the induction of apoptosis. Upregulation of a variety of apoptotic mediators further suggested that SNs induced cell death via apoptosis.

\section{Materials and methods}

SNs. SNs, with a particle size of $\sim 60 \mathrm{~nm}$, were provided by the College of Chemistry at Shandong University. Briefly, $2.5 \mathrm{ml}$ tetraethylorthosilicate was added to a premixed ethanol solution $(50 \mathrm{ml})$ containing $2 \mathrm{ml}$ of ammonia and $1 \mathrm{ml}$ of water. The mixture was stirred (150 RPM) at $40^{\circ} \mathrm{C}$ for $12 \mathrm{~h}$ and was then centrifuged at $11,294 \times \mathrm{g}$ and $37^{\circ} \mathrm{C}$ for $15 \mathrm{~min}$ to isolate the particles. After washing with deionized water three times, the particles were dispersed in $50 \mathrm{ml}$ of deionized water and sterilized by autoclaving $\left(0.1 \mathrm{MPa}, 120^{\circ} \mathrm{C}, 20 \mathrm{~min}\right)$ as a concentrated suspension for further experiments. SNs were dispersed in normal saline, which provided osmotic pressure comparable to that of cell fluid, sonicated with $20 \mathrm{KHz}$ at $37^{\circ} \mathrm{C}$ for $10 \mathrm{~min}$, and then, after standing for $24 \mathrm{~h}$, the morphology, particle size and dispersibility of the particles were observed via transmission electron microscopy (magnification, x100,000; JEM-2010; JEOL, Ltd.). Briefly, samples were prepared for TEM observation by dropping a 10-1 ethanol solution of ultrasonic dispersed SNs onto a 400-mesh carbon-coated copper grid. Image-Pro Plus software 6.0 (Media Cybernetics, Inc.) was used to analyze the data and calculate the mean particle size. SNs were diluted $(3 \mathrm{mg} / \mathrm{ml})$ with saline following exposure to high pressure, and the particle size distribution and polymerization state were monitored by dynamic light scattering using a particle size analyzer after standing at room temperature for 
$24 \mathrm{~h}$. The zeta potential and hydrodynamic size of the different concentrations of SNs in the dispersion medium (RPMI-1640; Gibco; Thermo Fisher Scientific, Inc.) were examined using a zeta-potential granulometer (Zeta Sizer 3000HS; Malvern Panalytical Ltd.).

Cell culture. Human normal hepatocyte HL-7702 cells were purchased from the Cell Resource Center, Shanghai Institutes for Biological Sciences (Chinese Academy of Sciences). HL-7702 cells were maintained in RPMI-1640 medium, containing $10 \%$ fetal bovine serum (Biological Industries) with $100 \mathrm{U} / \mathrm{ml}$ penicillin and $100 \mu \mathrm{g} / \mathrm{ml}$ streptomycin. Cells were incubated at $37^{\circ} \mathrm{C}$ in a $5 \% \mathrm{CO}_{2}$ humidified atmosphere and continuously passaged every 2-3 days. Cells were seeded in culture plates at a density of $1 \times 10^{5}$ cells $/ \mathrm{ml}$ for experiments. Following incubation for $24 \mathrm{~h}$, cells were treated with $\mathrm{SNs}$ dispersed in serum-free RPMI-1640 at concentrations of 0,25 , 50,100 or $200 \mathrm{mg} / \mathrm{ml}$ at $37^{\circ} \mathrm{C}$ for $24 \mathrm{~h}$. Cells maintained in RPMI-1640 without SNs were used as the control group.

Cell viability. The effects of SNs on cell viability were determined using an MTT assay according to the manufacturer's protocols. following exposure to various $\mathrm{SN}$ concentrations in serum-free RPMI-1640 $(0,25,50,100$, and $200 \mu \mathrm{g} / \mathrm{ml})$ at a density of 5,000 cells/sample in a 96-well plate for 12 and $24 \mathrm{~h}$, MTT was used to detect cell viability. Each group was set up in triplicate, and then $10 \mu \mathrm{l}$ MTT solution $(5 \mathrm{~g} / \mathrm{l})$ was added to each well and incubated for an additional $4 \mathrm{~h}$ at $37^{\circ} \mathrm{C}$. The optical density (OD) was detected at $490 \mathrm{~nm}$ using a microplate reader (Thermo Fisher Scientific, Inc.). The following formula was used to determine cell viability: $[(\mathrm{Ae}-\mathrm{Ab}) /(\mathrm{Ac}-\mathrm{Ab})] \times 100 \%$, where Ae is the experimental OD, $\mathrm{Ac}$ is the control OD, and $\mathrm{Ab}$ is the blank OD.

Hematoxylin and eosin $(H \& E)$ staining. H\&E staining was conducted to observe cell morphology. The cells, after grouping, were seeded into six-well plates at a density of $1 \times 10^{5}$ cells/sample. After exposure to $\mathrm{SNs}$ for $24 \mathrm{~h}$, cells were washed 3 times with PBS. Following fixation with 95\% ethanol at room temperature for $20 \mathrm{~min}$, hematoxylin was used to stain the nuclei at room temperature for $3 \mathrm{~min}$. After washing, the cytoplasm was stained with eosin at room temperature for $1 \mathrm{~min}$. Cells were then washed, naturally dried and sealed with neutral balsam, and morphological changes were observed under an optical microscope (magnification, x200; DM4000M; Leica Microsystems GmbH).

Giemsa staining assay. Briefly, $1 \times 10^{4}$ cells were inoculated onto clean and dry slides and exposed to SNs for $24 \mathrm{~h}$. The cells were fixed in formaldehyde at room temperature for $15 \mathrm{~min}$ and then stained with Giemsa (Beijing Solarbio Science \& Technology Co., Ltd.) at room temperature for $10 \mathrm{~min}$, according to the manufacturer's protocols. After staining, the cells were observed under an optical microscope (magnification, $x 400)$. In general, apoptotic cells stained blue and were darker in color than normal or necrotic cells.

Annexin V-FITC/propidium iodide (PI) apoptosis assay. Cells (1x $10^{4}$ cells/sample) were stained by $5 \mu 1$ Annexin V-FITC for $10 \mathrm{~min}$ and $5 \mu \mathrm{l}$ PI for $5 \mathrm{~min}$, respectively, at room temperature in the dark, according to the protocols provided by the manufacturer of an Annexin V-FITC/PI Apoptosis Assay kit (KGI Biosciences). The quantification of apoptosis induced by SNs in HL-7702 cells was conducted via flow cytometry (FCM; BD Biosciences); cells were collected and evaluated using CellQuest software (version 5.0; BD Biosciences), and apoptosis was analyzed by ModFit software (version 3.2; Verity Software House). The results are expressed as the rate of apoptosis (the percentage of early + late apoptotic cells).

Membrane potential detection. Rhodamine 123 is a cationic fluorescent dye that penetrates cell membranes and is an indicator of the MMP. Cells $\left(1 \times 10^{4}\right.$ cells/sample) were trypsinized with $0.25 \%$ trypsin for $2 \mathrm{~min}$, then mixed with $20 \mu \mathrm{g} / \mathrm{ml}$ Rhodamine 123 and incubated at $37^{\circ} \mathrm{C}$ in the dark for $30 \mathrm{~min}$. The MMP was detected via FCM (Beckman Coulter, Inc.), with an excitation wavelength of $488 \mathrm{~nm}$ and an emission wavelength of $525 \mathrm{~nm}$. Cells were evaluated using CellQuest software (version 5.0).

DNA damage assay. Damage of DNA in HL-7702 cells following treatment with $\mathrm{SNs}$ was analyzed using a Comet Assay kit (Trevigen; Bio-Techne). Cultured cells ( $1 \times 10^{5}$ cells/sample) were treated with SNs and harvested, and live cells were embedded within agarose on a glass slide. Cells were then lysed, and DNA was unwound under alkaline conditions, followed by electrophoresis $(1 \%)$ and $20 \mu \mathrm{g} / \mathrm{ml}$ ethidium bromide staining. Damaged DNA migrates towards the anode, leading to the appearance of comets; DNA damage was quantified by calculating the ratio of the tail length to the head diameter. Single-cell gel electrophoresis (SCGE) analysis was used to determine whether DNA damage had occurred in HL-7702 treated with SNs.

Cell cycle assay. Cultured cells ( $1 \times 10^{5}$ cells/sample) were trypsinized with $0.25 \%$ trypsin for $2 \mathrm{~min}$, and centrifuged at $1,000 \mathrm{x} \mathrm{g}$ for $5 \mathrm{~min}$ at room temperature, then pre-cooled $70 \%$ ethanol was added to the cell pellet and stored overnight at $4^{\circ} \mathrm{C}$. The cells were collected via centrifugation $(1,000 \mathrm{x} \mathrm{g})$ for $5 \mathrm{~min}$ at room temperature, following which $500 \mu \mathrm{l} \mathrm{PI}$ (Tianjin Sungene Biotech Co., Ltd.) was added, followed by FCM analysis. The results were analyzed using MultiCycle 6.0 (Phoenix Flow Systems, Inc.).

Immunocytochemistry. After fixing with $4 \%$ paraformaldehyde at room temperature for $15 \mathrm{~min}$, cells were permeabilized with $0.5 \%$ Triton-X-100 for 20 min and blocked with $3 \%$ hydrogen peroxide for $30 \mathrm{~min}$ at room temperature to block endogenous peroxidase. Cells were blocked with 5\% BSA (Beijing Solarbio Science \& Technology Co., Ltd.) at room temperature for $30 \mathrm{~min}$, followed by staining with primary and secondary antibodies, and then incubation for $10 \mathrm{~min}$ with DAB and 3 min with hematoxylin, both at room temperature. Immunocytochemistry was performed to detect the protein expression of Bax (1:500; cat. no. ab53154; Abcam), Bcl-2 (1:200; cat. no. ab59348; Abcam), Cyt C (1:1,000; cat. no. ab90529; Abcam) and caspase-3 (1:500; cat. no. ab13847; Abcam) using primary antibodies overnight at $4^{\circ} \mathrm{C}$. The secondary antibody used was horseradish peroxidase (HRP)-conjugated goat anti-rabbit (1:1,000; cat. no. ab214880; 
Abcam) for $1 \mathrm{~h}$ at room temperature. After staining, the cells were observed under an optical microscope. Brown or yellow-stained cells were quantified for positive staining for each high-power field (x400 magnification). Results are expressed as the total positive numbers of 50 random and continuous fields from each section using the software ImageJ (version 1.52; National Institutes of Health). All analyses were performed in a blinded manner without prior knowledge of the experimental groups.

Western blot assay. Western blotting was conducted to detect the expression of apoptosis-associated proteins. Following exposure to $0,25,50,100$ or $200 \mu \mathrm{g} / \mathrm{ml} \mathrm{SNs}$ as aforementioned, cells were cultured at $37^{\circ} \mathrm{C}$ in a $5 \% \mathrm{CO}_{2}$ incubator and cultured for $24 \mathrm{~h}$. Cells were washed with cold PBS 2-3 times and lysed in RIPA buffer (Beijing Solarbio Science \& Technology Co., Ltd.) for $30 \mathrm{~min}$ on ice. Cells were then centrifuged for $10 \mathrm{~min}\left(8,430 \mathrm{x} \mathrm{g}\right.$ at $\left.4^{\circ} \mathrm{C}\right)$, and the supernatants were collected for protein determination using the BCA method (Beyotime Institute of Biotechnology). Protein samples $(50 \mu \mathrm{g})$ were separated via SDS-PAGE (10\% resolving gels, 5\% stacking gels) and transferred to PVDF membranes (300 mA, $1.5 \mathrm{~h})$. The membranes were blocked with $5 \%$ nonfat dry milk for $1 \mathrm{~h}$ at room temperature, followed by incubation with the aforementioned primary antibodies (at a dilution of 1:1,000 for Bax, 1:1,000 for Bcl-2, 1:2,000 for caspase-3 and 1:1,000 for Cyt C) and anti-GAPDH antibody (1:20,000; cat. no. 10494-1-AP, ProteinTech Group. Inc.) overnight at $4^{\circ} \mathrm{C}$. After washing with TBS-0.05\% Tween 20 (TBST), the membranes were incubated with HRP-conjugated goat anti-rabbit secondary antibodies (cat. no. ab6721; Abcam) at 1:10,000 dilutions for 1.5 h at room temperature, followed by a further wash with TBST, prior to exposure to an enhanced chemiluminescence reagent (ECL detection kit; Pierce; Thermo Fisher Scientific, Inc.). Finally, the membranes were exposed to an Odyssey CLx near-infrared fluorescence imaging system (LI-COR Biosciences). Results were quantified using AlphaEaseFC software (version 4.0; ProteinSimple). All experiments were conducted in triplicate.

Statistical analysis. All statistical analysis was performed using Prism 5 (GraphPad Software, Inc.). Data are presented as the mean \pm SEM. One-way ANOVA with Dunnett's post hoc test was used to compare across multiple treatments. Experiments were repeated three times with at least triplicate wells per condition. $\mathrm{P}<0.05$ was considered to indicate a statistically significant difference.

\section{Results}

Characterization of SNs. As presented in Fig. 1 and Table I, SNs were spherical, with an average particle size of $60.80 \pm 4.36 \mathrm{~nm}$, and good dry dispersion characteristics in the absence of aggregation. Zeta potential analysis revealed that different concentrations of SNs in serum-free RPMI-1640 medium were negatively charged, and the absolute value of the zeta potential was $\sim-20 \mathrm{eV}$, with good dispersion (Table II).

Effects of SNs on cell viability. A decrease in viability was observed for HL-7702 cells that were exposed to SNs for $12 \mathrm{~h}$, with a significant difference emerging at $200 \mu \mathrm{g} / \mathrm{ml}$ compared

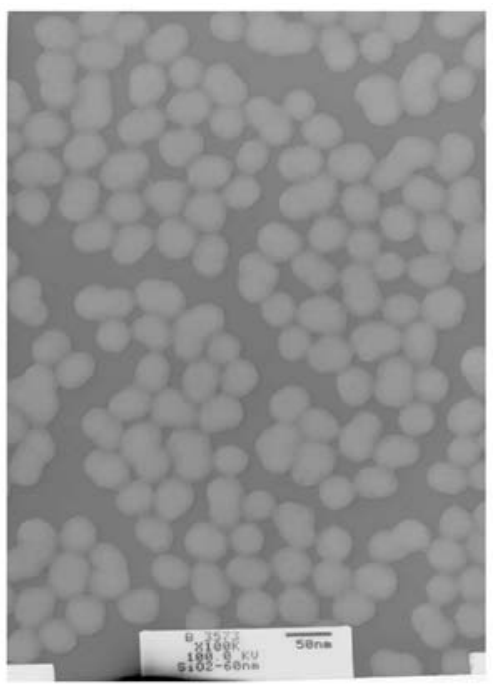

Figure 1. Transmission electron microscopy of silica nanoparticles. Magnification, x100,000.

with the control $(\mathrm{P}<0.05$; Fig. 2). Cell viability decreased further with increasing exposure time $(24 \mathrm{~h})$, specifically at the concentrations of $50-200 \mu \mathrm{g} / \mathrm{ml}(\mathrm{P}<0.05)$, with decreases in cell viability at 100 and $200 \mu \mathrm{g} / \mathrm{ml}$ of $24.6 \pm 4.3$ and $44.5 \pm 0.09 \%$, respectively. These results indicated that SNs reduced the viability of HL-7702 cells.

Effects of SNs on cell morphology. A number of morphological changes were observed following incubation of HL-7702 cells with SNs for $24 \mathrm{~h}$. The control group resembled polygons with large and round nuclei, located in a central nucleus with well-defined nucleoli; conversely, following treatment with $50 \mu \mathrm{g} / \mathrm{ml} \mathrm{SNs}$, cell swelling was evident and nuclei were mildly vacuolated (Fig. S1). With an increase in dose, the cell volume decreased, changes to the cytoplasm and nuclear vacuoles were notable, the chromatophore basophilic edge set was enhanced, the cytoplasm was dense, the eosinophilicity was enhanced and apoptotic bodies formed. At the highest concentration $(200 \mu \mathrm{g} / \mathrm{ml})$, nuclear membrane thickening, cell body shrinkage, nuclear pyknosis and disintegration were evident, indicating the occurrence of apoptosis (Fig. S1E). In summary, cells treated with SNs exhibited morphological changes associated with apoptosis.

Morphological changes in HL-7702 cells indicating apoptosis caused by SNs. Giemsa staining was employed to detect apoptosis in HL-7702 cells treated with SNs. In cells stained with Giemsa, nuclei are stained blue or purple-blue, and the cytoplasm is stained pink under a light microscope (34). In the present study, normal nuclei stained purple-blue and exhibited uniform color following Giemsa staining (Fig. S2). Conversely, there was nuclear hyperchromatism, shrinkage, edge aggregation and the formation of densely stained apoptotic bodies in the SN treatment groups. As presented in Fig. S2, with increasing concentrations of SNs, the number of cells was reduced, cells shrunk, the intercellular space increased, the cell volume decreased, the cytoplasm permeability disappeared, the cell surface became prominent and apoptotic body formation was evident. 
Table I. Characterization of silica nanoparticles.

\begin{tabular}{lc}
\hline Characterization & $\begin{array}{c}\text { Silica nanoparticles } \\
(60 \mathrm{~nm})\end{array}$ \\
\hline $\begin{array}{lc}\text { Size and distribution }(\mathrm{nm}, \text { mean } \pm \mathrm{SD}) \\
\text { Hydrodynamic size in normal }\end{array}$ & $60.80 \pm 4.36$ \\
saline $(\mathrm{nm})$ & 99.5 \\
Shape & Spheroidicity \\
\hline
\end{tabular}

Table II. Zeta potential of silica nanoparticles in RPMI-1640 medium $(\mathrm{n}=5)$.

\begin{tabular}{lc}
\hline Concentration $(\mu \mathrm{g} / \mathrm{ml})$ & Zeta potential $(\mathrm{eV})$ \\
\hline 25 & $-18.40 \pm 1.79$ \\
50 & $-23.29 \pm 1.70$ \\
100 & $-18.24 \pm 0.76$ \\
200 & $-22.75 \pm 1.00$ \\
\hline
\end{tabular}

Flow cytometric analysis of SN-induced apoptosis in HL-7702 cells. Annexin V-FITC/PI double staining and a flow cytometer were used to detect apoptosis. A significant increase in apoptosis was observed at concentrations of SNs of $50-200 \mu \mathrm{g} / \mathrm{ml}$, varying between $25-40 \%$ apoptosis by $24 \mathrm{~h}$ $(\mathrm{P}<0.05$; Fig. 3F).

Effects of SNs on the MMP. As a dose-dependent increase in apoptosis was observed following exposure to SNs, Rhodamine 123 was used to monitor the MMP in treated cells. Exposure of HL-7702 cells to SNs for $24 \mathrm{~h}$ induced a significant decrease in MMP at $25 \mu \mathrm{g} / \mathrm{ml}$, which decreased further with increasing concentrations of SNs $(\mathrm{P}<0.05$; Fig. 4).

Treatment with SNs induces DNA damage. SCGE and an alkaline comet assay were used to determine the levels of DSBs in cultured HL-7702 cells treated with various concentrations of SNs. Whereas control cells appeared to be largely spherical, cells treated with different concentrations of SNs exhibited cell trailing or tail formation, indicating the formation of DSBs, which increased with the concentration of SNs (Fig. 5).

Effects of SNs on the cell cycle. FCM analysis revealed that HL-7702 cells treated with SNs exhibited a significantly decreased percentage of cells in $G_{0} / G_{1}$ phase after $24 \mathrm{~h}$, whereas the $\mathrm{S}$ and $\mathrm{G} 2 / \mathrm{M}$ phase proportions significantly increased (Fig. 6). These results indicated that, following exposure to SNs, cells were impeded in their cycle progression and accumulated in the G2/M phase (Fig. 6F).

Effects of SNs on Bcl-2, Bax, Cyt C and Caspase-3 expression. It was demonstrated via immunocytochemistry that exposure of HL-7720 cells to increasing concentrations of SNs induced a significant increase in the number of Bax-positive, Bcl-2-positive, Cyt C-positive and caspase-3-positive cells $(\mathrm{P}<0.05$; Figs. 7A and S3-S6). Furthermore, western blotting

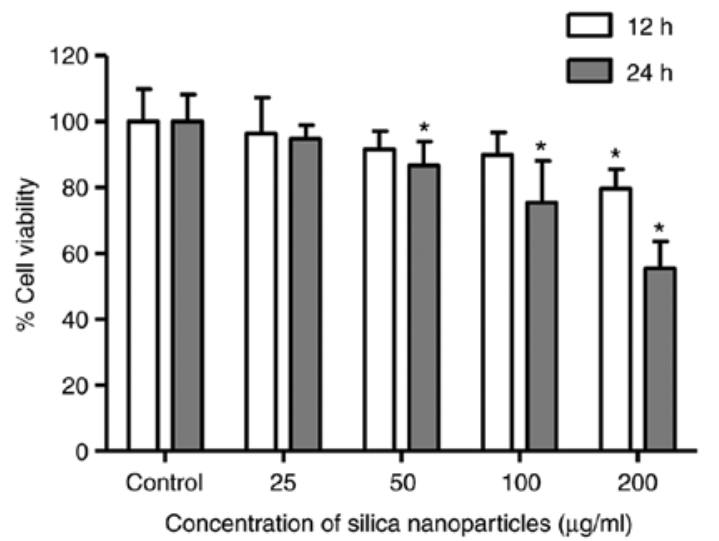

Figure 2. Viability of HL-7702 human hepatocytes. Cells were treated with $25,50,100$ or $200 \mu \mathrm{g} / \mathrm{ml} \mathrm{SN}$ solutions, or control treatment without SNs, for 12 and 24 h. ${ }^{*} \mathrm{P}<0.05$ vs. control. SN, silica nanoparticle.

revealed that $\mathrm{SN}$ treatment significantly increased Bax expression and decreased the Bcl-2/Bax ratio ( $\mathrm{P}<0.05$; Fig. 7B-D). The expression levels of $\mathrm{Cyt} \mathrm{C}$ and caspase-3 were also significantly upregulated following treatment with increasing concentrations of SNs, compared with control group $(\mathrm{P}<0.05$; Fig. 7C and D).

\section{Discussion}

SNs are widely used in materials science, as catalysts and catalyst carriers, food additives and cosmetics, and particularly for biomedical applications, including in clinical diagnosis, as drugs and DNA carriers, and as biosensors (17). The aim of the present study was to investigate the effects of SNs on apoptotic cell death, and to determine the potential underlying mechanisms in HL-7702 cells in vitro. The study was designed to improve understanding regarding the effects of SNs on the human hepatic system and explore the potential mechanisms, to improve application safety.

Nanoparticles of different particle sizes have distinct biological and toxicological effects; it is generally accepted that the smaller the particle size, the greater the biological effects $(35,36)$. In the present study, human hepatocytes were exposed to 60-nm particles with a zeta potential of $\sim-20 \mathrm{eV}$ and good dispersion. A previous study reported that smaller particles (80 $\mathrm{nm}$ in diameter) entered cells more easily and induced more potent effects on the physiological functions of cells compared with larger particles (500 $\mathrm{nm}$ in diameter) (37). In addition, it has been demonstrated that the surface features of nanoparticles are major factors affecting their biological effectiveness $(38,39)$, for example, small nanoparticles can be endocytosed by cells, resulting in cytotoxicity, whereas large aggregates adhere onto the cell surface and increase the growth rate of cells (40). Briefly, in the present study, SNs were spherical, with an average particle size of $60.80 \pm 4.36 \mathrm{~nm}$, and with good dispersion; thus, the characteristics of the particles used in the present study were optimal for investigating the mechanisms underlying silica-induced toxicity using HL-7702 cells as an in vitro hepatic model system (41). In the present study, uniform size (60-nm) particles were used; nanoparticles of other diameters remain to be investigated. Previous studies 
A

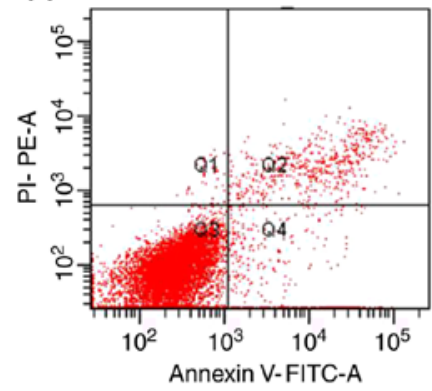

D

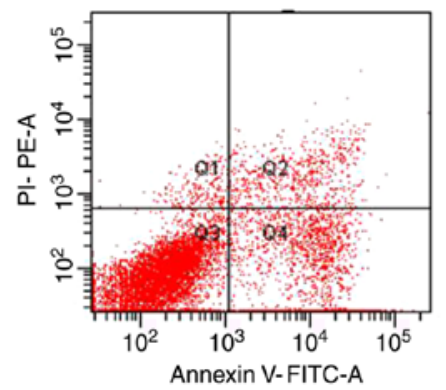

B

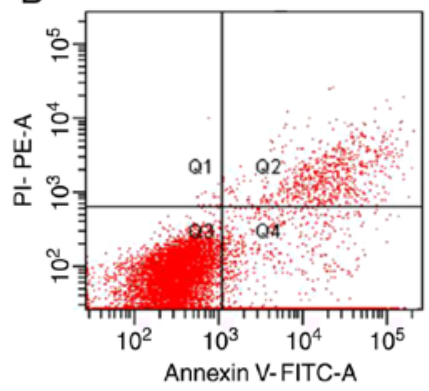

E

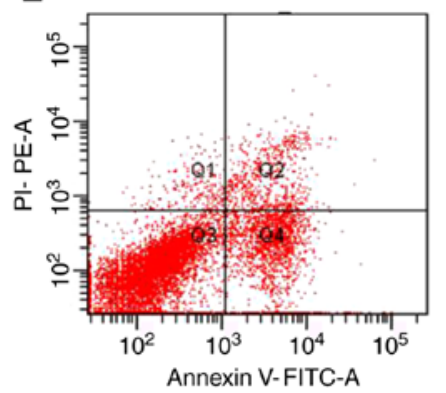

C

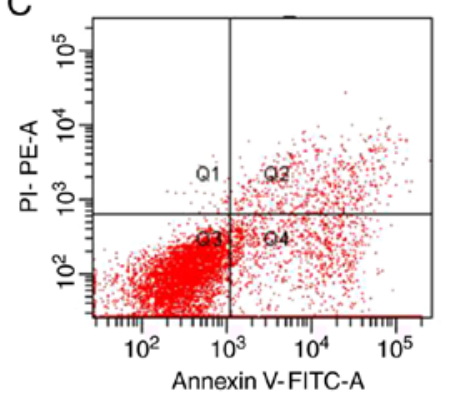

$\mathrm{F}$

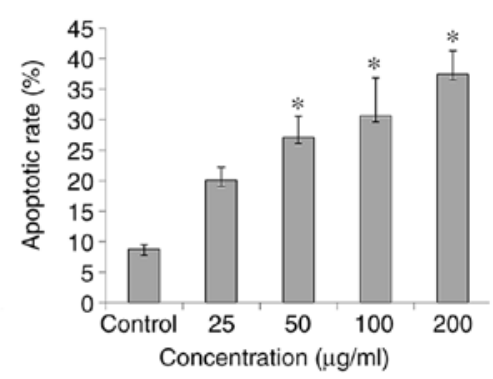

Figure 3. Effects of SNs on the apoptosis of HL-7702 cells. (A) Cells exposed to basal medium without SNs for $24 \mathrm{~h}$ were observed. Cells exposed to (B) 25, (C) 50 , (D) 100 and (E) $200 \mu \mathrm{g} / \mathrm{ml}$ of SNs were analyzed via flow cytometry. (F) Apoptotic rates of HL-7702 cells treated with different concentrations of SNs for $24 \mathrm{~h}$ as determined using a flow cytometer. ${ }^{*} \mathrm{P}<0.05$ vs. control. PI, propidium iodide; $\mathrm{SN}$, silica nanoparticle.

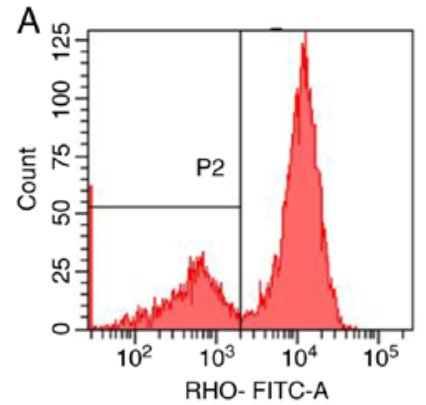

D

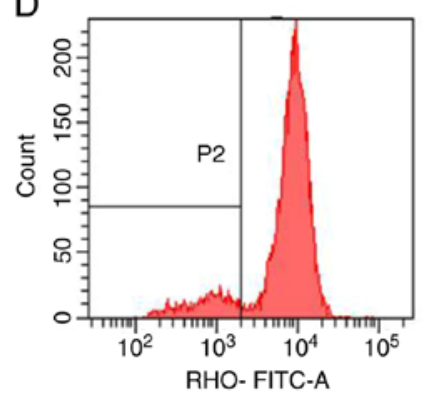

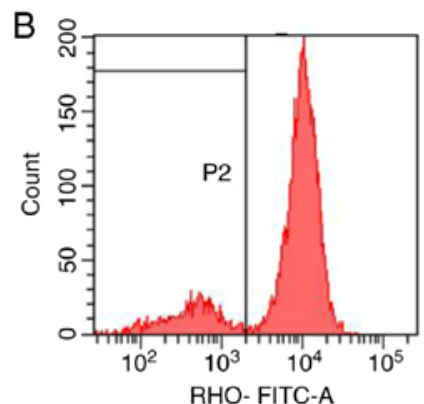

$\mathrm{E}$

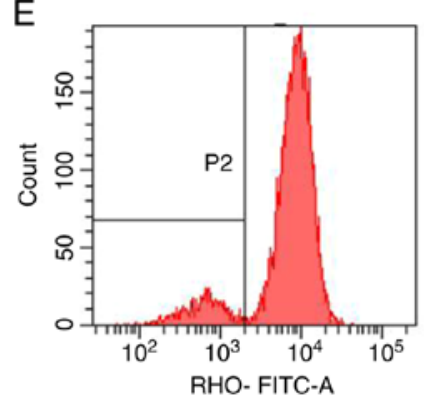

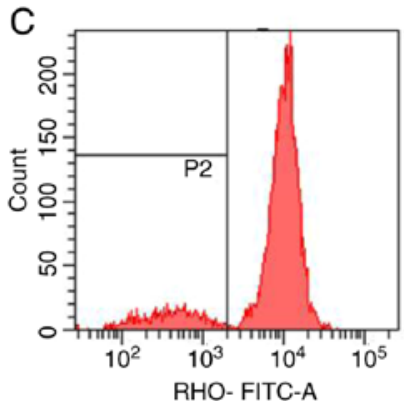

$\mathrm{F}$

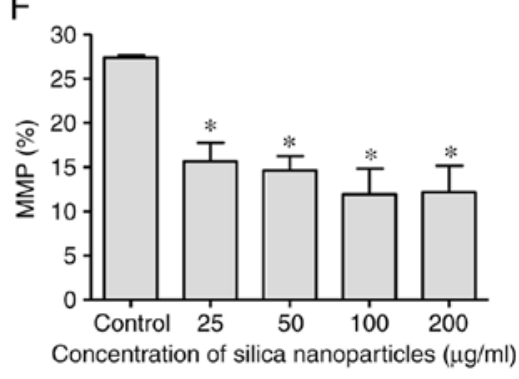

Figure 4. Effects of SNs on the MMP of HL-7702 cells. Evaluation of the MMP of (A) control-treated HL-7702 cells, and cells treated with (B) 25, (C) 50, (D) 100 and (E) $200 \mu \mathrm{g} / \mathrm{ml} \mathrm{SNs}$ for $24 \mathrm{~h}$. The vertical axis indicates the number of cells and the horizontal axis indicates the MMP. (F) Quantification of the effects of SN treatment on the MMP as determined via flow cytometry. " $\mathrm{P}<0.05$ vs. control. MMP, mitochondrial membrane potential; RHO, Rhodamine 123 ; SN, silica nanoparticles.

have reported that, following intraperitoneal injection of an $\mathrm{SN}$ suspension in mice, nanoparticles were distributed to the liver, heart, spleen, lung, kidney and other tissues $(15,17)$, and induced acute and chronic liver injury (42). The present study provided evidence that SNs were cytotoxic to the HL-7702 liver cell line, and that the mechanism of cell killing was predominantly via apoptosis.
In vivo experiments have indicated the hepatotoxicity of SNs. For example, acute liver failure occurred following long-term injection of 70-nm SNs in mice, and histological analysis confirmed accumulation in the liver (43). Furthermore, 30-nm silica particles were also demonstrated to induce hepatotoxicity via in vivo experiments in mice (44). Additionally, a similar in vitro study reported that SNs induced apoptosis in a dose-dependent 
A

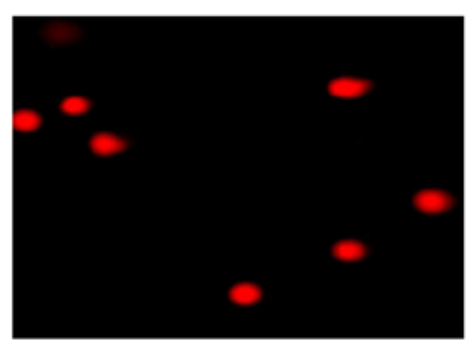

D

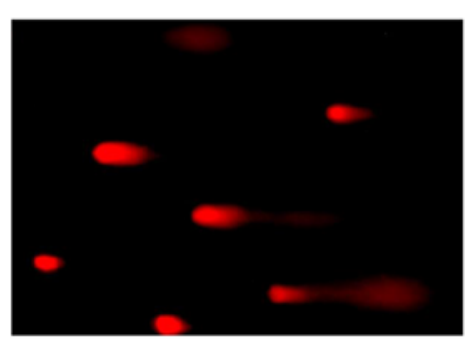

B

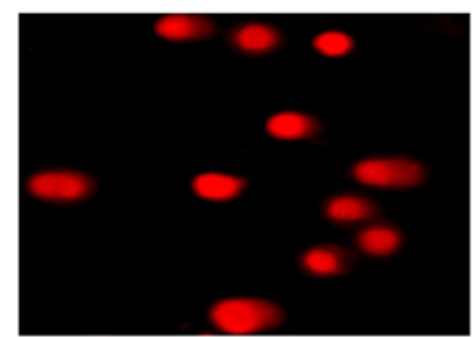

E

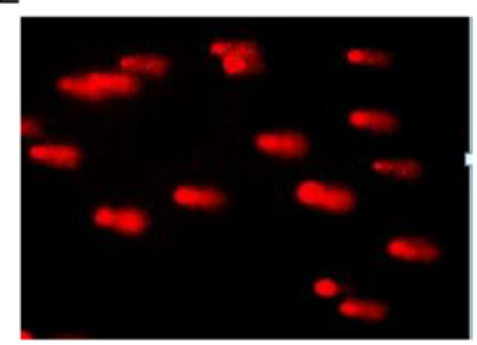

C

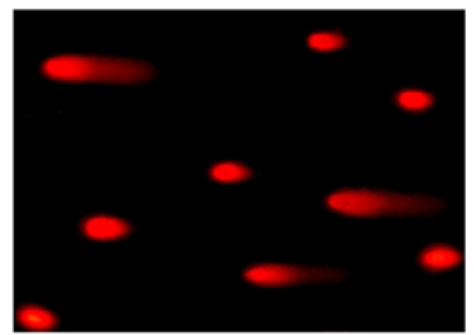

$\mathrm{F}$

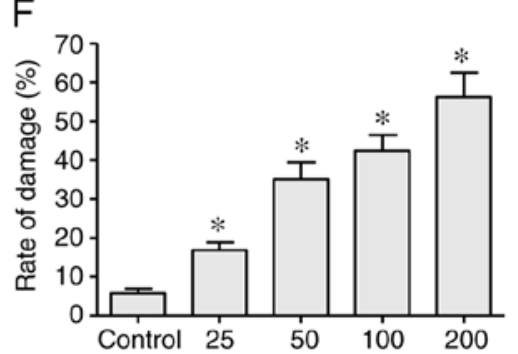

Concentration of silica nanoparticles $(\mu \mathrm{g} / \mathrm{ml})$

Figure 5. DNA damage in HL-7702 cells treated with SNs. Evaluation of DNA damage in (A) control-treated HL-7702 cells, and cells treated with (B) 25, (C) 50, (D) 100 and (E) $200 \mu \mathrm{g} / \mathrm{ml} \mathrm{SNs}$ for $24 \mathrm{~h}$. Cells were subjected to single-cell gel electrophoresis; cells possessing double-strand breaks exhibit comet-like tails during electrophoresis. (F) Quantification of the effects of SN treatment on DNA damage. " $\mathrm{P}<0.05$ vs. control. SN, silica nanoparticle.

A



$\mathrm{D}$

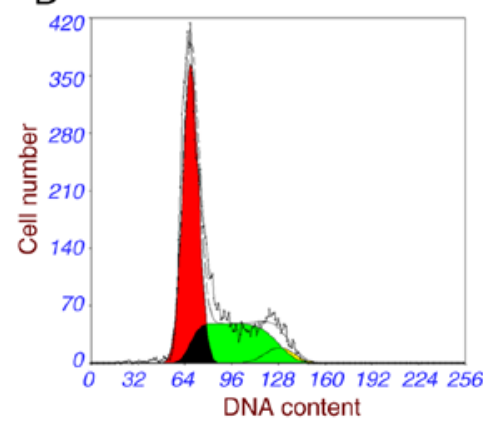

B

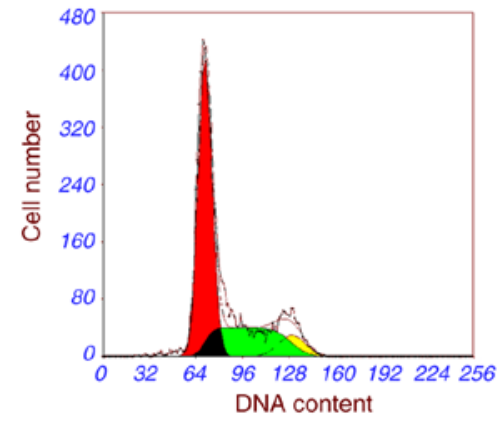

$\mathrm{E}$

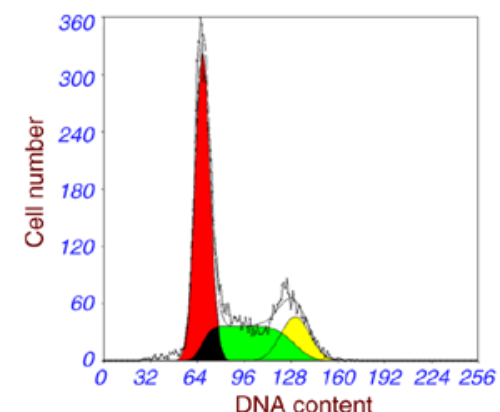

C

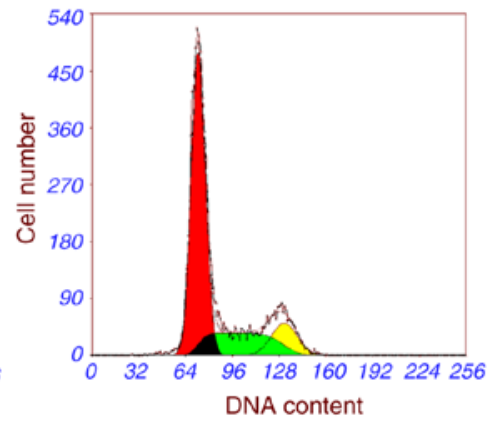

$\mathrm{F}$

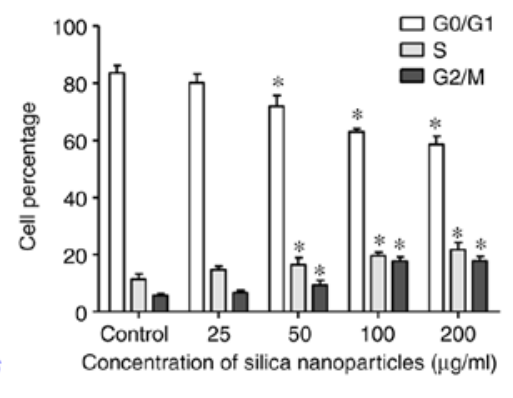

Figure 6. Cell cycle arrest in HL-7702 cells treated with SNs. Cell cycle analysis of (A) control-treated HL-7702 cells, and cells treated with (B) 25, (C) 50, (D) 100 and (E) $200 \mu \mathrm{g} / \mathrm{ml} \mathrm{SNs}$ for $24 \mathrm{~h}$. (F) Quantification of the effects of SN treatment on the cell cycle distribution as determined via flow cytometry. ${ }^{*} \mathrm{P}<0.05$ vs. control. SN, silica nanoparticles.

manner in HepG2 liver cancer cells (45). An additional in vitro study reported that SNs can penetrate cell membranes and deposit in organelles, altering protein expression and the outer MMP, and inducing cell cycle arrest, DNA damage and cell death (46). The present study corroborated these effects of SNs, as cell cycle arrest, DNA damage, a decrease in the MMP and apoptosis were observed in SN-treated HL-7702 cells.
In the present study, cell division was arrested in the G2/M phase following SN exposure, which was associated with reduced cell viability and the induction of cell death. Accumulating evidence indicates that manipulation of the cell cycle may prevent or induce an apoptotic response (47). The G2/M DNA damage checkpoint is an important cell cycle checkpoint in eukaryotic organisms ranging from yeast 

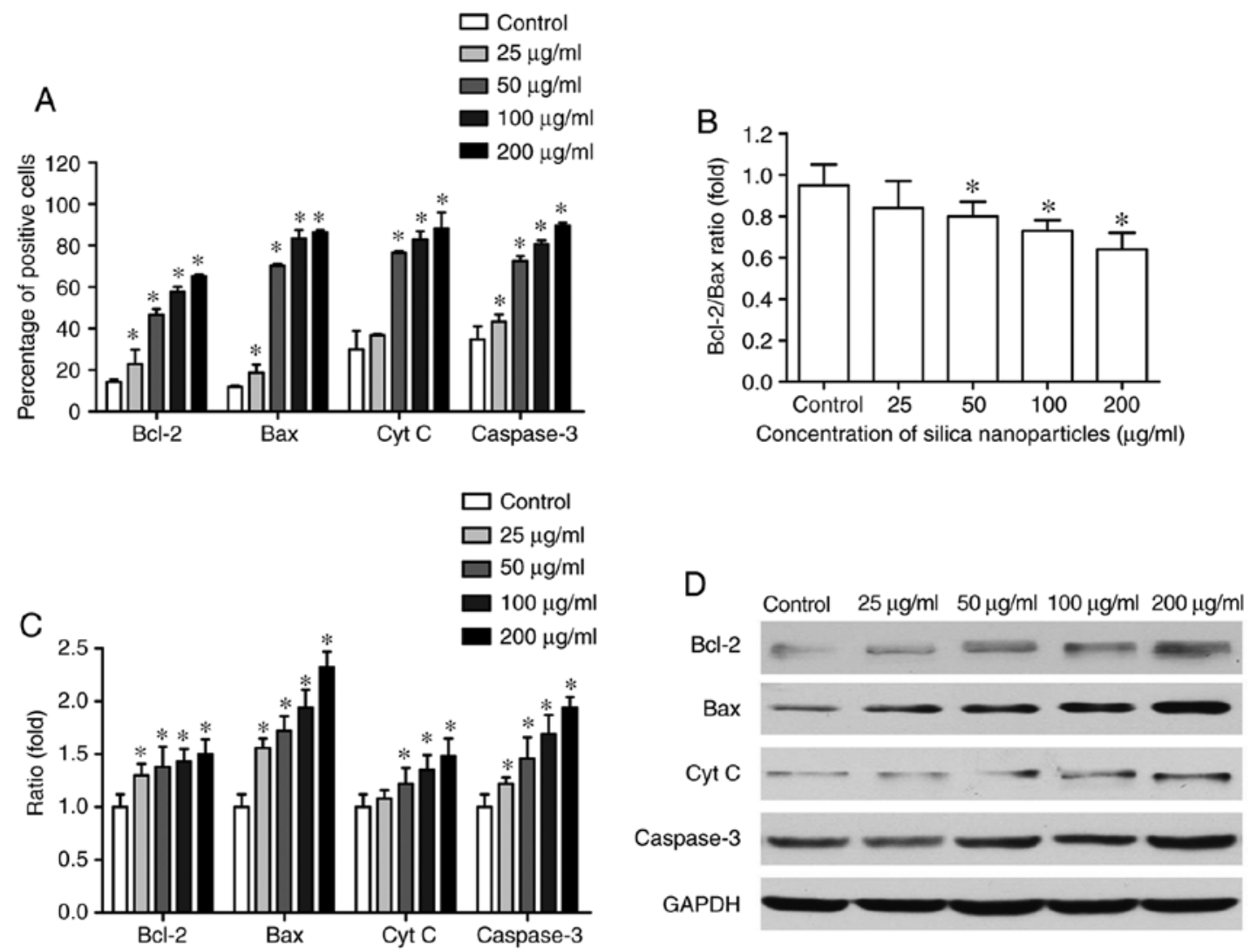

Figure 7. Effects of SNs on apoptosis-associated protein expression in HL-7702 cells. (A) Effects of SNs on Bcl-2, Bax, Cyt C and Caspase-3 expression in HL-7702 cells, as determined by immunocytochemistry and diaminobenzidine staining. Cells were treated with $25,50,100$, or $200 \mu \mathrm{g} / \mathrm{ml} \mathrm{SNs,} \mathrm{or} \mathrm{control}$ treatment without SNs, for $24 \mathrm{~h}$, and the percentage of cells exhibiting positive expression of the various proteins was determined. (B) Bcl-2/Bax ratio in cells treated with SNs as aforementioned. (C) Expression of Bcl-2, Bax, Cyt C and caspase-3 protein in cells treated as aforementioned, as determined by western blotting. (D) Western blot analysis of Bcl-2, Bax, Cyt C and Caspase-3 protein expression in HL-7702 cells treated as aforementioned. GAPDH was used as the internal control. ${ }^{*} \mathrm{P}<0.05$ vs. control $(\mathrm{n}=5)$. Cyt $\mathrm{C}$, cytochrome $\mathrm{C}$; $\mathrm{SN}$, silica nanoparticle.

to mammals, ensuring that cells don't initiate mitosis until damaged DNA or incompletely replicated DNA is sufficiently repaired after replication (48). Cells that have a defective G2/M checkpoint enter mitosis before repairing their DNA, leading to apoptosis or death after cell division (49). When the cell receives a signal that it is not conducive to division, or the timing is immature, the cell will stop at the subsequent cell cycle checkpoint for examination; if an irreparable error is found, the cell initiates apoptosis (48). In the present study, it was determined that, following exposure to increasing concentrations of SNs, the cell cycle was arrested in the G2/M phase, potentially leading to the induction of apoptosis.

The MMP is generated by the asymmetric distribution of protons and other ions on the two sides of the mitochondrial inner membrane, and depolarization of the MMP is a specific and early marker of apoptosis (50). It occurs prior to the characteristic nuclear changes in apoptosis, such as chromatin condensation and DSBs (51). SNs may penetrate the cell membrane and remain in the mitochondria, leading to mitochondrial and cellular damage (52), suggesting that SNs may cause apoptosis via the mitochondrial pathway (3). This is consistent with the present findings, as a dose-dependent disruption of the MMP was detected in SN-treated HL-7702 cells, potentially leading to the observed induction of apoptosis in these cells. Furthermore, progression to apoptosis is irreversible when the MMP collapses (53). A similar study has also observed that the loss of the MMP and disruption of the mitochondrial ultrastructure are associated with apoptosis, and that SNs can induce an increase in ROS, further exacerbating cellular toxicity (54).

Apoptosis involves multiple genes that strictly control the process, including the Bcl-2 and caspase families (55). In the present study, the expression of both Bcl-2 and Bax was increased, inconsistent with the induction of apoptosis; however, the Bcl-2/Bax ratio decreased with increasing SN concentrations, indicating a proapoptotic state in cells (56). A decreased $\mathrm{Bcl}-2 / \mathrm{Bax}$ ratio has been shown to reduce cellular resistance to apoptotic stimuli, leading to apoptosis (57). When $\mathrm{Bcl}-2$ expression is higher than that of Bax, it forms homodimers, and apoptosis is inhibited. When Bax expression is higher than that of Bcl-2, Bax-Bax homodimers are formed and apoptosis is promoted. When the HepG2 human hepatocyte cell line was treated with SNs, the mRNA and protein expression levels of proapoptotic genes were upregulated, whereas antiapoptotic genes, such as Bcl-2, were downregulated, resulting in the induction of apoptosis in a dose-dependent manner (21), consistent with the present study in HL-7702 cells.

In conclusion, it was revealed that SNs induced apoptosis in HL-7702 cells, potentially via the release of Cyt C from mitochondria and activation of caspase 3 , and changes in the expression of apoptosis-associated proteins in the mitochondrial signaling pathway. SNs increased the protein expression of Bax and Bcl-2 in HL-7702 cells, but decreased the Bcl-2/Bax 
ratio. The present study only focused on one $\mathrm{SN}$ particle size and one signaling pathway; whether SNs can induce apoptosis via other pathways, such as receptor-mediated or endoplasmic reticulum pathways, remains to be investigated in future studies.

\section{Acknowledgements}

The authors would like to thank Professor Jinhua Zhan and Dr Nianzhu Li (Shandong University) for the preparation of silica nanoparticles.

\section{Funding}

The present study was funded by National Natural Science Foundation of China (grant nos. 81573198, 81602893 and 81872575), the Natural Science Foundation of Shandong Province (grant nos. ZR2015YL049 and ZR2018MH036), the Natural Science Foundation of Jiangsu Province (grant no. BK20140573], the Medical and Health) Technology Development Plan Project of Shandong Province (grant no. 2016WS0540), the Key Research and Development Plan of Shandong Province (grant nos. 2017GSF18186, 2017GSF18142 and 2018GSF118018) and the Innovation Project of Shandong Academy of Medical Science.

\section{Availability of data and materials}

The datasets used and/or analyzed during the present study are available from the corresponding author on reasonable request.

\section{Authors' contributions}

YY, XJD, QW, JWL and ZJD conceived and designed the study. YY, XJD, LLS, EGZ and XY performed the experiments. YY and XJD drafted the paper. CP, AJY, HS and MFL designed the study, analyzed the data, and critically reviewed and edited the manuscript. All authors read and approved the final manuscript.

\section{Ethics approval and consent to participate}

Not applicable.

\section{Patient consent for publication}

Not applicable.

\section{Competing interests}

The authors declare that they have no competing interests.

\section{References}

1. Powers KW, Brown SC, Krishna VB, Wasdo SC, Moudgil BM and Roberts SM: Research strategies for safety evaluation of nanomaterials. Part VI. Characterization of nanoscale particles for toxicological evaluation. Toxicol Sci 90: 296-303, 2006.

2. Lu X, Qian J, Zhou H, Gan Q, Tang W, Lu J, Yuan Y and Liu C: In vitro cytotoxicity and induction of apoptosis by silica nanoparticles in human HepG2 hepatoma cells. Int J Nanomedicine 6 : 1889-1901, 2011
3. Kumar P, Tambe P, Paknikar KM and Gajbhiye V: Mesoporous silica nanoparticles as cutting-edge theranostics: Advancement from merely a carrier to tailor-made smart delivery platform. J Control Release 287: 35-57, 2018.

4. Park JH, Dumani DS, Arsiwala A, Emelianov S and Kane RS Tunable aggregation of gold-silica janus nanoparticles to enable contrast-enhanced multiwavelength photoacoustic imaging in vivo. Nanoscale 10: 15365-15370, 2018.

5. Müller K, Fedosov D and Gompper G: Margination of microand nano-particles in blood flow and its effect on drug delivery. Sci Rep 4: 4871, 2014

6. Mebert AM, Baglole CJ, Desimone MF and Maysinger D: Nanoengineered silica: Properties, applications and toxicity. Food Chem Toxicol 31: 753-770, 2017.

7. Pietroiusti A, Stockmann-Juvala H, Lucaroni F and Savolainen K: Nanomaterial exposure, toxicity, and impact on human health. Wiley Interdiscip Rev Nanomed Nanobiotechnol, Feb 23, 2018 (Epub ahead of print).

8. Laux P, Tentschert J, Riebeling C, Braeuning A, Creutzenberg O, Epp A, Fessard V, Haas KH, Haase A, Hund-Rinke K, et al: Nanomaterials: Certain aspects of application, risk assessment and risk communication. Arch Toxicol 92: 121-141, 2018.

9. Guo M, Xu X, Yan X, Wang S, Gao S and Zhu S: In vivo biodistribution and synergistic toxicity of silica nanoparticles and cadmium chloride in mice. J Hazard Mater 260: 780-788, 2013.

10. Chen N, Song ZM, Tang H, Xi WS, Cao A, Liu Y and Wang H: Toxicological effects of Caco-2 cells following short-term and long-term exposure to Ag nanoparticles. Int J Mol Sci 17: pii: E974, 2016.

11. Ahamed M: Silica nanoparticles-induced cytotoxicity, oxidative stress and apoptosis in cultured A431 and A549 cells. Hum Exp Toxicol 32: 186-195, 2013.

12. Lewinski N, Colvin V and Drezek R: Cytotoxicity of nanoparticles. Small 4: 26-49, 2008.

13. Oberdörster G, Oberdörster E and Oberdörster J: Nanotoxicology: An emerging discipline evolving from studies of ultrafine particles. Environ Health Perspect 123: 823-839, 2005.

14. Yoshida T, Yoshioka Y, Tochigi S, Hirai T, Uji M, Ichihashi K, Nagano K, Abe Y, Kamada H, Tsunoda S, et al: Intranasal exposure to amorphous nanosilica particles could activate intrinsic coagulation cascade and platelets in mice. Part Fibre Toxicol 10: 41, 2013.

15. Du Z, Zhao D, Jing L, Cui G, Jin M, Li Y, Liu X, Liu Y, Du H, Guo C, et al: Cardiovascular toxicity of different sizes amorphous silica nanoparticles in rats after intratracheal instillation. Cardiovasc Toxicol 13: 194-207, 2013.

16. Lin W, Huang YW, Zhou XD and Ma Y: In vitro toxicity of silica nanoparticles in human lung cancer cells. Toxicol Appl Pharmacol 217: 252-259, 2006

17. Kim JS, Yoon TJ, Yu KN, Kim BG, Park SJ, Kim HW, Lee KH, Park SB, Lee JK and Cho MH: Toxicity and tissue distribution of magnetic nanoparticles in mice. Toxicol Sci 89: 338-347, 2006.

18. Wu J, Wang C, Sun J and Xue Y: Neurotoxicity of silica nanoparticles: Brain localization and dopaminergic neurons damage pathways. ACS Nano 5: 4476-4489, 2011.

19. Erren TC, Glende CB, Morfeld P and Piekarski C: Is exposure to silica associated with lung cancer in the absence of silicosis? A meta-analytical approach to an important public health question. Int Arch Occup Environ Health 82: 997-1004, 2009.

20. Mignotte B and Vayssiere JL: Mitochondria and apoptosis. Eur J Biochem 252: 1-15, 1998.

21. Ahmad J, Ahamed M, Akhtar MJ, Alrokayan SA, Siddiqui MA, Musarrat J and Al-Khedhairy AA: Apoptosis induction by silica nanoparticles mediated through reactive oxygen species in human liver cell line HepG2. Toxicol Appl Pharmacol 259: 160-168, 2012.

22. Gopinath P, Gogoi SK, Sanpui P, Paul A, Chattopadhyay A and Ghosh SS: Signaling gene cascade in silver nanoparticle induced apoptosis. Colloids Surf B Biointerfaces 77: 240-245, 2010.

23. Katiyar SK, Roy AM and Baliga MS: Silymarin induces apoptosis primarily through a p53-dependent pathway involving $\mathrm{Bcl}-2 / \mathrm{Bax}$, cytochrome c release, and caspase activation. Mol Cancer Ther 4: 207-216, 2005.

24. Korsmeyer SJ, Shutter JR, Veis DJ, Merry DE and Oltvai ZN: Bcl-2/Bax: A rheostat that regulates an anti-oxidant pathway and cell death. Semin Cancer Biol 4: 327-332, 1993.

25. Mariño G, Niso-Santano M, Baehrecke E and Kroemer G: Self-consumption: The interplay of autophagy and apoptosis. Nat Rev Mol Cell Biol 15: 81-94, 2014. 
26. Yu Y, Duan J, Yu Y, Li Y, Liu X, Zhou X, Ho KF, Tian L and Sun Z: Silica nanoparticles induce autophagy and autophagic cell death in HepG2 cells triggered by reactive oxygen species. J Hazard Mater 270: 176-186, 2004.

27. Buratti $S$ and Lavine JE: Drugs and the liver: Advances in metabolism, toxicity, and therapeutics. Curr Opin Pediatr 14 601-607, 2002

28. Liu T, Li L, Teng X, Huang X, Liu H, Chen D, Ren J, He J and Tang F: Single and repeated dose toxicity of mesoporous hollow silica nanoparticles in intravenously exposed mice. Biomaterials 32: 1657-1668, 2011.

29. Yoshida T, Yoshioka Y, Matsuyama K, Nakazato Y, Tochigi S, Hirai T, Kondoh S, Nagano K, Abe Y, Kamada H, et al: Surface modification of amorphous nanosilica particles suppresses nanosilica-induced cytotoxicity, ROS generation, and DNA damage in various mammalian cells. Biochem Biophys Res Commun 427: 748-752, 2012.

30. Sun L, Li Y, Liu X, Jin M, Zhang L, Du Z, Guo C, Huang P and Sun Z: Cytotoxicity and mitochondrial damage caused by silica nanoparticles. Toxicol In Vitro 25: 1619-1629, 2011.

31. Chen Q, Xue Y and Sun J: Kupffer cell-mediated hepatic injury induced by silica nanoparticles in vitro and in vivo. Int J Nanomedicine 8: 1129-1140, 2013.

32. Li N, Duan Y, Hong M, Zheng L, Fei M, Zhao X, Wang J, Cui Y, Liu H, Cai J, et al: Spleen injury and apoptotic pathway in mice caused by titanium dioxide nanoparticules. Toxicol Lett 195: 161-168, 2010.

33. Isoda K, Tetsuka E, Shimizu Y, Saitoh K, Ishida I and Tezuka M: Liver injury induced by thirty- and fifty-nanometer-diameter silica nanoparticles. Biol Pharm Bull 36: 370-375, 2013.

34. Zhu Z, Li E, Liu Y, Gao Y, Sun H, Ma G, Wang Z, Liu X, Wang Q, Qu X, et al: Inhibition of Jak-STAT3 pathway enhances bufalin-induced apoptosis in colon cancer SW620 cells. World J Surg Oncol 10: 228, 2012.

35. Nel A, Xia T, Mädler L and Li N: Toxic potential of materials at the nanolevel. Science 311: 622-627, 2006.

36. Kipen HM and Laskin DL: Smaller is not always better: Nanotechnology yields nanotoxicology. Am J Physiol Lung Cell Mol Physiol 289: L696-L697, 2005

37. Zhang Y, Hu L, Yu D and Gao C: Influence of silica particle internalization on adhesion and migration of human dermal fibroblasts. Biomaterials 31: 8465-8474, 2010.

38. Ryman-Rasmussen JP, Riviere JE and Monteiro-Riviere NA: Surface coatings determine cytotoxicity and irritation potential of quantum dot nanoparticles in epidermal keratinocytes. J Invest Dermatol 127: 143-153, 2007.

39. Chan WT, Liu CC, Chiang Chiau JS, Tsai ST, Liang CK, Cheng ML, Lee HC, Yeung CY and Hou SY: In vivo toxicologic study of larger silica nanoparticles in mice. Int J Nanomedicine 12 $3421-3432,2017$

40. Cui W, Li J, Zhang Y, Rong H, Lu W and Jiang L: Effects of aggregation and the surface properties of gold nanoparticles on cytotoxicity and cell growth. Nanomedicine 8: 46-53, 2012

41. Guo C, Ma R, Liu X, Chen T, Li Y, Yu Y, Duan J, Zhou X, Li Y and Sun Z: Silica nanoparticles promote oxLDL-induced macrophage lipid accumulation and apoptosis via endoplasmic reticulum stress signaling. Sci Total Environ 631-632: 570-579, 2018.
42. Nishimori H, Kondoh M, Isoda K, Tsunoda S, Tsutsumi $\mathrm{Y}$ and Yagi K: Silica nanoparticles as hepatotoxicants. Eur J Pharm Biopharm 72: 496-501, 2009.

43. Nishimori $\mathrm{H}$, Kondoh $\mathrm{M}$, Isoda $\mathrm{K}$, Tsunoda S, Tsutsumi $\mathrm{Y}$ and Yagi K: Histological analysis of 70-nm silica particles-induced chronic toxicity in mice. Eur J Pharm Biopharm 72: 626-629, 2009.

44. So SJ, Jang IS and Han CS: Effect of micro/nano silica particle feeding for mice. J Nanosci Nanotechnol 8: 5367-5371, 2008

45. Yu Y, Duan J, Yu Y, Li Y, Zou Y, Yang Y, Jiang L, Li Q and Sun Z: Autophagy and autophagy dysfunction contribute to apoptosis in HepG2 cells exposed to nanosilica. Toxicol Res (Camb) 5: 871-882, 2016.

46. Duan J, Yu Y, Li Y, Yu Y, Li Y, Zhou X, Huang P and Sun Z: Toxic effect of silica nanoparticles on endothelial cells through DNA damage response via Chk1-dependent G2/M checkpoint. PLoS One 8: e62087, 2013.

47. Vermeulen K, Berneman ZN and Van Bockstaele DR: Cell cycle and apoptosis. Cell Prolif 36: 165-175, 2003.

48. Stark GR and Taylor WR: Analyzing the G2/M checkpoint. Methods Mol Biol 280: 51-82, 2004

49. Cuddihy AR and O'Connell MJ: Cell-cycle responses to DNA damage in G2. Int Rev Cytol 222: 99-140, 2003.

50. Ly JD, Grubb R and Lawen A: The mitochondrial membrane potential (deltapsi(m)) in apoptosis; an update. Apoptosis 8: 115-128, 2003.

51. Green DR and Kroemer G: The pathophysiology of mitochondrial cell death. Science 305: 626-629, 2004.

52. Li Y, Sun L, Jin M, Du Z, Liu X, Guo C, Li Y, Huang P and Sun Z Size-dependent cytotoxicity of amorphous silica nanoparticles in human hepatoma HepG2 cells. Toxicol In Vitro 25: 1343-1352, 2011.

53. Pucci B, Adams CS, Fertala J, Snyder BC, Mansfield KD, Tafani M, Freeman T and Shapiro IM: Development of the terminally differentiated state sensitizes epiphyseal chondrocytes to apoptosis through caspase-3 activation. J Cell Physiol 210: 609-615, 2007.

54. Krętowski R, Kusaczuk M, Naumowicz M, Kotyńska J, Szynaka B and Cechowska-Pasko M: The effects of silica nanoparticles on apoptosis and autophagy of glioblastoma cell lines. Nanomaterials (Basel) 7: pii: E230, 2017.

55. Gross A, Mcdonnell JM and Korsmeyer SJ: BCL-2 family members and the mitochondria in apoptosis. Genes Dev 13: 1899-1911, 1999.

56. Brenner C, Cadiou H, Vieira HL, Zamzami N, Marzo I, Xie Z, Leber B, Andrews D, Duclohier H, Reed JC and Kroemer G: $\mathrm{Bcl}-2$ and Bax regulate the channel activity of the mitochondrial adenine nucleotide translocator. Oncogene 19: 329-336, 2000.

57. Gao C and Wang AY: Significance of increased apoptosis and Bax expression in human small intestinal adenocarcinoma. J Histochem Cytochem 57: 1139-1148, 2009.

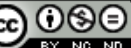

This work is licensed under a Creative Commons Attribution-NonCommercial-NoDerivatives 4.0 International (CC BY-NC-ND 4.0) License. 